\title{
A study about Protective Effect of Brevibacillus laterosporus texasporus Culture on Broiler Chickens Infected with Salmonella Pullorum
}

Mhd Adanan Purba ${ }^{1}$, , Shoaib Ahmed Pirzado ${ }^{1,}$,Huiyi Cai ${ }^{1}$, Tesfay Hagos Haile ${ }^{1}$,Aijuan Zheng ${ }^{1}$, Jiao Liu ${ }^{1}$, Jiang Chen $^{1}$, Nurzainah Ginting ${ }^{2}$, Yunilas ${ }^{2}$ and Guohua Liu ${ }^{1 *}$

${ }^{1}$ The Key Laboratory of Feed Biotechnology of Ministry of Agriculture, National Engineering Research Center of Biological Feed,Feed Research Institute, Chinese Academy of Agricultural Sciences, Zhongguancun Nandajie 12, Beijing, China

${ }^{2}$ Animal Production Program Study, Faculty Of Agriculture, University Of Sumatera Utara, Medan, Indonesia. *Corresponding Author: Prof. Liu Guohua Tel.:+86-1082105477, Fax number:+86-1082106077,

Email : liuguohua@caas.cn

\begin{abstract}
A demand for chicken-meat is growing enormously which requires intensification in the production, so it iscrucial to improve the chicken health condition.The aim of this study is to investigate the effects of Brevibacillus laterosporus texasporus culture (BT) to the growth, immunity and blood parameters of broilers and also to determine whether the culture has a potential to act as a probiotic supplement of the fodder. A total of 300 one-day-old male Arbor Acres broilers chickens were randomly assigned to 5 treatments with 6 replications $(10$ individualsin each replicate) i.e.the positive control (PC)which had no challenge ofSalmonella Pullorum wasadministered inthe basal diet. Meanwhile, the negative control (NC) challenged by Salmonella Pullorumper os was administered in three form of diets, and these were included inthe diet with the composition of kitasamycin for $10 \mathrm{mg} / \mathrm{kg}$ as antibiotics growth promotor, BT for $50 \mathrm{mg} / \mathrm{kg}$, and BT for $100 \mathrm{mg} / \mathrm{kg}$. The live body weight $(L B W)$ and average daily body weight gain (ADG) of initial period were upregulated $(P<0.05)$, while at the end of the period, the results displayed the changes in $L B W(P=0.304)$ and $A D G(P=0.672)$. Based on the analysis of Enzymelinked immunosorbent assay (ELISA), the $\operatorname{Ig} G(g / L)$ showed no significant values, and the $\operatorname{IgM}(g / L)$ significantly rose after 21 days, while the $\operatorname{IgA}(g / L)$ showed significant values after 42 days. The chicken c-reactive protein (CRP) was found to be significantly changes on day 9, and the significant values in lipopolysaccharide (LPS) and monoamine oxidase (MAO) were found which respectively on the day 9 to 42 and 21; the diamine oxidase (DAO) changes were found after 42 days. The treatment diet of AGP and BT100 have affectedless histological changes in liver tissues than BT5O and NC. These findings suggested that BT could protect the chickens from the adverse impacts of Salmonella infection, andthese can be used as a feed additive to promote health and growth.
\end{abstract}

Keywords : Brevibacillus laterosporus texasporus culture, Salmonella, Broilers, Growth, Immune, inflamination

\section{INTRODUCTION}

Salmonella is one of the most common pathogenic microorganisms in poultry industry. Its infection could cause salmonellosis in poultry flock in form several types, including chicken pullorum disease caused by Salmonella pullorum, fowl typhoid caused by salmonella typhi, and fowl paratyphoid caused by some other salmonella bacteria. Salmonellosis in poultry is widespread throughout the world and it causes great enormous loss to the poultry industry. The most common infectious disease of salmonella for broiler chickens is pullorum which delays the development and growth of chickens particularly below 10 days-old via systematic infection, that leads to diarrhea, and even death. Therefore, the control of Salmonella pullorum is the key point of broiler chicken 
breeding. In several decades, traditional strategy to control chicken pullorum as well as other bacterial infections depends on the use of a broad-spectrum of antibiotics. However, the widespread use of antimicrobials has resulted in increasing trends on the multi-drug resistance bacteria. Over several decades, this has led to the selection pressures, and it has fostered to the emergence and the spread of antibiotic resistant pathogens, in which countries across the world acknowledge this magnitude as a global threat. Additional concerns have been generated along with the increasing number of discoveries on antibiotic-resistant isolates of Salmonella and Campylobacter.

On the other hand, the use of antibiotics in poultry feed has led to bacterial resistance to multiple antibiotics in isolation from poultry products (Page \& Gautier, 2012). Meat products contaminated with antibiotic resistant bacteria now appear to cause most human cases of food-borne bacterial infections. The removal of antimicrobial growth promoters (AGP) from poultry diets has triggered many researchersin finding suitable alternatives as well as to combat the increased potentials for chicken pullorum and other development of bacterial diseases.

Probiotics can be defined as living microorganisms that can establish colonies in animal intestinal tracts and they can improve the micro-ecological balance of the host. These microorganisms can also increase the feed intake (Karimi-Kivi, Dadashbeiki, \& Seidavi, 2015), the growth (Suo et al., 2012), as well as the immunity improvement of the chickens due to the presence of lactobacilli. On the other hand, they also can decrease the numbers of salmonellacolonies in the animal gut (Afsharmanesh, Sadaghi, \& Silversides, 2013). These types of bacteria also can improve the enzymatic contribution in digestive systems. One of the microorganisms that is used as a probioticis the Bacillus group sincethis species can improve the growth performance of animals and is also able to inhibit the growth of pathogenic bacteria in the gut of most animals.It is known that microbes produce a variety of secondary metabolites to compete with other microbes for ecological niches. Brevibacillus laterosporus texasporus (BT) (ATCC PTA-5854) is a recently identified soil bacterium that produces a group of cationic NRPS peptides (WO 2005/074626), (X. Wu, Ballard, \& Jiang, 2005). The cationic peptides from BT display a broad-spectrum of antibacterial activity in in-vitro, killing the Gram positive and negative bacteria, fungi and protozoa (WO 2005/074626). Meanwhile, Brevibacillus brevis(B. brevis) has a broad-spectrum of antimicrobial activities, so that this bacterial species becomes a novel candidate for a biocontrol agent (Seddon et al. 2000). TheB. brevis has been reported to be able in preventing fusarial wilt symptoms in tomato, lettuce, pigeon pea, cucumber and watermelon plants (Bapat \& Shah, 2000; Seddon et al. 2000; Ge et al. 2009) B. brevis FJAT- 0809GLX could inhibit the growth of Lasiodiplodia theobromae on postharvest of wax-apple fruit (Che, Liu, Ruan, Tang, \& Huang, 2015) . This species also has been reported that a strain of B. brevis FJAT- 1501-BPA can inhibit the growth of E. Coli K88, Salmonella typhimurium ATCC14028 and Staphylococcus aureus (Ge et al. 2009), implying the potential features as a probiotic in animal feeding.

The aim of this study is to investigate the effects of Bacillus laterosporus Texasporus (BT) on growth performances, carcass traits, immunity and blood parameters of broilers and to determine whether Bacillus Lateropus texasporus has a protective role for broiler chickens infected with Salmonella Pullorum.

\section{MATERIALS AND METHODS}

\section{Location and Duration}

The experiment was conducted at the Nankou Animal Testing Base and Microbiology Laboratory of Feed Research Institute, Chinese Academy of Agricultural Sciences, starting from September 2018 until October 2019

\section{Experimantal Design, Animal and Diets}

A single-factor completely random design was employed in this experiment. A total of 300 one-day-old male Arbor Acres Plus broilers were divided randomly into 5 treatment groups which was experimented for 6 replications with 10 birds per replicates. The treatments included a positive control (PC) without Salmonella Pulloruminfection and this group was fed with basal diet, whereas the negative control (NC) challenged by Salmonella Pullorumper os and this group was administered with basal diet. The other three groups with Salmonella Pullorum challenge infection were administered with three different experimental diets, which were prepared by adding $10 \mathrm{mg} / \mathrm{kg}$ kitasamycin as antibiotics growth promotor (AGP), $50 \mathrm{mg} / \mathrm{kg}$ BT (BT50), or $100 \mathrm{mg} / \mathrm{kg} \mathrm{BT}$ (BT100) 
in the basal diet.

The basal diet composition was made of corn, soybean meal, cottonseeds meal and other feeding ingredients. No any antibiotics growth promotor or probiotics was added. The ingredient composition and nutrients content are shown in Table 1.

Table 1. Composition and calculated analysis of basal diets fed to broilers.

\begin{tabular}{lll}
\hline Composition & Starter & Finisher \\
\hline Corn & Formula & \\
Soybean oil & 64.38 & 69.32 \\
Soybean meal & 0.15 & 0.92 \\
Cottonseeds meal & 25.68 & 18.47 \\
Table salt & 5 & 7.00 \\
Dicalcuim phosphorate & 0.3 & 0.30 \\
Limestone & 1.49 & 1.28 \\
Lys chloride & 1.61 & 1.51 \\
DL-Methionine & 0.38 & 0.37 \\
L-threonine & 0.25 & 0.20 \\
Choline chloride & 0.06 & 0.03 \\
Vitamin\&mineral premix & 0.2 & 0.10 \\
\hline
\end{tabular}

\section{Nutrient level}

\begin{tabular}{|c|c|c|}
\hline $\mathrm{AME}(\mathrm{kcal} / \mathrm{kg})$ & 2950 & 3050 \\
\hline Crude protein $(\%)$ & 20.00 & 18.00 \\
\hline Lysine $(\%)$ & 1.200 & 1.050 \\
\hline Methionine (\%) & 0.531 & 0.453 \\
\hline $\operatorname{TSAA}(\%)$ & 0.900 & 0.800 \\
\hline Threonine(\%) & 0.850 & 0.720 \\
\hline Tryptophan (\%) & 0.274 & 0.237 \\
\hline Calcuim(\%) & 1.000 & 0.900 \\
\hline Phosphorus (\%) & 0.662 & 0.618 \\
\hline Available phosphorus (\%) & 0.450 & 0.420 \\
\hline
\end{tabular}




\section{Feeding management}

The experiment was conducted at Nankou Animal Experiment Station of the Chinese Academy of Agricultural Sciences. The broiler chickens were domesticated in a feeding trial room with a set of stainless steel cage system. Room temperature was controlled at $32^{\circ} \mathrm{C}$ at the first week and it was decreased gradually to $22^{\circ} \mathrm{C}$ by $2{ }^{\circ} \mathrm{C}$ of declining rateeach week by using natural gas heating system. Artificial light was kept for 24 hours daily, and the birds could access to diets and water ad libitum. The entire experiment lasted for 42 days and was carried strictly by followingthe Implementation of the Regulations of the Chinese Academy of Agricultural Sciences on Biosafety and Animal Welfare Management.

\section{Salmonella Challenge}

In this experiment, a model of Salmonella Pullorum infection in broilers was employed. At $7.00 \mathrm{am}, 7$-days-of-age and 8-days-of-age of samples within the challenge groups were fed with 0.4 $\mathrm{ml}$ of Salmonella Pullorum inoculum $\left(1 \times 10^{9} \mathrm{CFU} / \mathrm{mL}\right)$ freshly cultured, and each of the birds of PC group was fed with $0.4 \mathrm{ml}$ medium sterilized broth.

\section{Growth Performance and Death Rate Statistics}

The diet intake and body weight of broilers were scaled on the $21^{\text {st }}$ and $42^{\text {th }}$ day, and the ratio to body weigh gain (FCR) was calculated. The broiler condition and manure were observed daily, and their mortality was calculated at the age of 42 days.

\section{Serum Biochemical Analysis}

On the day of $9^{\text {th }}, 21^{\text {st }}$ and $42^{\text {nd }}$, the chicken subjects that had the average weight from every replication test were selected in order to collect their blood samples via wing vein puncture. The serum was obtained for the analysis, in which the concentration of serum immunoglobulin A (IgA), immunoglobulin $\mathrm{G}(\mathrm{IgG})$ and immunoglobulin $\mathrm{M}(\mathrm{IgM})$, C-reactive protein (CRP), monoamine oxidase (MAO), diamine oxidase (DAO), lipopolysaccharide (LPS) were measured by using ELISA kits (Elabscience Biotechnology Co, Ltd, China) according to the manufacturer's instructions.

\section{Liver Histopathological Examination}

On the day of 21 , chicken samples from every replication test were sacrificed via cervical dislocation to collect the histopathological examination. The big lobe of liver was removed, and it was immersed into an amount formalin solution for 48 hours. The sections with $5-\mu \mathrm{m}$ thick were prepared and dyed in hematoxylin-eosin solution. The tissue structure of liver was observed at 400x magnification using a digital microscope (BX 4, 3Olympus Tokyo, Japan). Ten visual fields of each section were randomly selected to be photographed for veterinarypathology examination.

\section{Statistical Analysis}

All data were analyzed using SPSS software (IBM-SPSS Inc., Chicago, IL). An one-way analysis of variance (ANOVA) was used to evaluate the treatmental effects. Tukey HSD was employed for mutiple comarison of means. The values were expressed as. All statement of significance was considered at $\mathrm{P}<0.05$

\section{RESULTS AND DISCUSSION}

\section{Growth performance}

The mean values of LBW and BWG are presented in Table 3.

Table 3. Effects of BT on body weight and growth rate of broilers

\begin{tabular}{lccccccc}
\hline Parameter & PC & NC & AGP & BT50 & BT100 & SEM & P-Value \\
\hline D1-21 & & & & & & & \\
LBW & $803^{\mathrm{a}}$ & $690^{\mathrm{b}}$ & $785^{\mathrm{a}}$ & $682^{\mathrm{b}}$ & $760^{\mathrm{a}}$ & 14 & 0.006 \\
ADG & $37.96^{\mathrm{a}}$ & $32.30^{\mathrm{b}}$ & $37.03^{\mathrm{ab}}$ & $31.90^{\mathrm{b}}$ & $36.19^{\mathrm{a}}$ & 0.70 & 0.006 \\
\hline D22-42 & & & & & & & \\
LBW & 2415 & 2301 & 2363 & 2356 & 2428 & 20 & 0.304 \\
ADG & 76.74 & 76.72 & 75.14 & 79.71 & 79.42 & 1.10 & 0.672 \\
\hline
\end{tabular}

1-42 days 


$\begin{array}{llllllll}\text { ADG } & 57.82 & 55.05 & 56.55 & 56.39 & 58.14 & 0.50 & 0.304\end{array}$

Means with different superscripts within a row were significantly different $(P<0.05)$. LBW= Live body weight, $\mathrm{ADG}=$ Average daily weight gain. $. \mathrm{PC}=$ Positive Control, $\mathrm{NC}=$ negative control, $\mathrm{AGP}=$ $10 \mathrm{ppm}$ kitasamycin, $\mathrm{NC} 50=50 \mathrm{ppm}$ BT, $\mathrm{NC} 100=100 \mathrm{ppm}$ BT.

The mean values of LBW and BWG are presented in Table 3. LBW and ADG on the starter period significantly $(\mathrm{P}<0.05)$ increased with the supplementation of BT100 compared to NC and BT50, while no significant differences were found between BT100, PC and AGP. There was no significant effect found in LBW and ADG on $22^{\text {nd }}-42^{\text {nd }}$ days among all treatments, however numerical differences were recorded between BT100 and other treatments during the day of $22^{\text {nd }}-42^{\text {nd }}$ and $11^{\text {st }}$ $42^{\text {nd }}$.

In the beginning period which was $1^{\text {st }}-21^{\text {st }}$ day, the treatments had a significant effect $(\mathrm{P}$ $<0.05$ ) on the LBW and ADG. The birds from NC and NC50 groups had the lowest LBW and ADG, which were lower significantly than PC. The AGP and BT100 groups had the medium growth rate falling in between PC and NC without significant difference of value compared to other treatments. It indicated that salmonella challenge obviously delayed the growth of broiler chicken in the starter period, and the dietary addition of $10 \mathrm{ppm}$ kitasamycin or $100 \mathrm{ppm}$ BT overcame the detriment from salmonella strain to some extent. However, kitasamycin and Bacillus brevis Texasporus culture couldnoteliminate the reverse effect of salmonella thoroughly.

At the end of the period, experimental treatment had no influence to the growth. It seems that the adverse effect of challenging pathogen disappeared with the increase of age. Numerically, addition of BT in diets has improved the growth rate from 21 to 42 day-old. For the whole period, the group of BT100 showed the greatest LBW, NC hadthe lowest one although no significant differences were found.

\section{Serum Immune Global Protein}

The effects of bacillus lateropus texasporus culture to the content of immunoglobulin are displayed in Table 4.

Table 4. Effect of Bacillus Brevis Texasporus cluture on serum immune global protein of Broilers.

\begin{tabular}{lccccccc}
\hline Parameter & PC & NC & AGP & BT50 & BT100 & SEM & P-Value \\
\hline 9 days & & & & & & & \\
$\operatorname{IgA}(\mathrm{g} / \mathrm{L})$ & 2.37 & 2.33 & 2.38 & 2.38 & 2.33 & 0.010 & 0.184 \\
$\operatorname{IgG}(\mathrm{g} / \mathrm{L})$ & $4.10^{\mathrm{a}}$ & $3.95^{\mathrm{a}}$ & $4.09^{\mathrm{a}}$ & $3.85^{\mathrm{b}}$ & $3.96^{\mathrm{a}}$ & 0.031 & 0.047 \\
$\operatorname{IgM}(\mathrm{g} / \mathrm{L})$ & $1.68^{\mathrm{a}}$ & $1.52^{\mathrm{b}}$ & $1.60^{\mathrm{a}}$ & $1.51^{\mathrm{b}}$ & $1.60^{\mathrm{a}}$ & 0.018 & 0.008 \\
\hline $\mathbf{2 1 ~ d a y s}$ & & & & & & & \\
$\operatorname{IgA}(\mathrm{g} / \mathrm{L})$ & 2.30 & 2.34 & 2.29 & 2.26 & 2.26 & 0.012 & 0.207 \\
$\operatorname{IgG}(\mathrm{g} / \mathrm{L})$ & 4.08 & 4.16 & 4.37 & 4.19 & 4.28 & 0.034 & 0.069 \\
$\operatorname{IgM}(\mathrm{g} / \mathrm{L})$ & $1.57^{\mathrm{b}}$ & $1.69^{\mathrm{a}}$ & $1.62^{\mathrm{ab}}$ & $1.71^{\mathrm{a}}$ & $1.65^{\mathrm{ab}}$ & 0.015 & 0.010 \\
\hline $\mathbf{4 2} \mathbf{d a y s}$ & & & & & & & \\
$\operatorname{IgA}(\mathrm{g} / \mathrm{L})$ & $2.16^{\mathrm{a}}$ & $2.04^{\mathrm{c}}$ & $2.09^{\mathrm{ab}}$ & $2.14^{\mathrm{a}}$ & $2.18^{\mathrm{a}}$ & 0.013 & 0.001 \\
$\operatorname{IgG}(\mathrm{g} / \mathrm{L})$ & 4.28 & 4.39 & 4.49 & 4.38 & 4.20 & 0.038 & 0.139 \\
$\operatorname{IgM}(\mathrm{g} / \mathrm{L})$ & 1.68 & 1.69 & 1.71 & 1.64 & 1.62 & 0.014 & 0.333
\end{tabular}

${ }^{\mathrm{a}-\mathrm{d}}$ Means with different superscripts within a row were significantly different $(P<0.05) . \operatorname{IgA}=$ immunoglobulin $\mathrm{A}, \mathrm{IgG}=$ immunoglobulin $\mathrm{G}, \mathrm{IgM}=$ immunoglobulin $\mathrm{M} . \mathrm{PC}=$ Positive Control, $\mathrm{NC}=$ negative control, $\mathrm{AGP}=10 \mathrm{ppm}$ kitasamycin, $\mathrm{NC} 50=50 \mathrm{ppm}$ BT, $\mathrm{NC} 100=100 \mathrm{ppm}$ BT. 
The effects of Bacillus lateropus texasporus culture to the content of immunoglobulin are displayed inTable 4. The results on the 9th day showed the significant different $(\mathrm{P}<0.05)$ in IgG and IgM level serum. The PC group demonstrated higher content of $\mathrm{IgG}(\mathrm{P}>0.05)$, whereasthe $\operatorname{IgM}$ displayed higher value in significant number $(\mathrm{P}<0.05)$ than $\mathrm{NC}$ or BT50, and the values of AGP and BT100 are in between of IgG and IgM. It appears that the addition of kitasamycin or $100 \mathrm{mg} / \mathrm{kg} \mathrm{BT}$ overcomes the nagetive effect of Salmonella partly on $\operatorname{IgG}$ and $\operatorname{IgM}(\mathrm{P}>0.05)$.

The obvious treatment effect on IgM could still be observed on the day of $21^{\text {st }}(\mathrm{P}<0.05)$. The $\mathrm{NC}$ and BT50 had more significant effect to IgM serum level than that in PC $(\mathrm{P}<0.01)$, and AGP and BT100 were in between of them without demonstrating significant difference $(\mathrm{P}>0.05)$. Obviously, Salmonella stimulated the arising of IgM in serum, and kitasamycin or $100 \mathrm{mg} / \mathrm{kg}$ BT restrained the change of IgM content.

On the 42 days of age, the effects on IgM and IgG disppeared. However, the content of IgA changed during the treatment days $(\mathrm{P}<0.05)$. BT100 was found to contributein higer level of IgA than that in AGP and BT50 $(\mathrm{P}<0.05)$. Salmonella had no effect to the contents of IgA in serum $(\mathrm{P}>0.05)$

\section{Serum Inflammatory Markers}

In this experiment, some serum inflammatory markers were investigated, included the chicken Creactive protein (CRP), lipopolysaccharide (LPS), monoamine oxidase (MAO) and diamine oxidase (DAO). Table 4 shows the effects of Bacillus lateropus texasporus culture on these inflammatory makers.

Table 5. Effect of Bacillus Brevis Texasporus cluture on inflammatory markers in serum of broilers.

\begin{tabular}{lccccccc}
\hline Parameter & PC & NC & AGP & BT50 & BT100 & SEM & P-Value \\
\hline 9 days & & & & & & & \\
CRP(mg/L) & $5.14^{\mathrm{a}}$ & $4.91^{\mathrm{a}}$ & $3.51^{\mathrm{b}}$ & $4.35^{\mathrm{ab}}$ & $3.97^{\mathrm{b}}$ & 0.167 & 0.004 \\
LPS(EU/ml) & $0.43^{\mathrm{b}}$ & $0.47^{\mathrm{ab}}$ & $0.50^{\mathrm{a}}$ & $0.49^{\mathrm{a}}$ & $0.44^{\mathrm{b}}$ & 0.008 & 0.009 \\
DAO(U/L) & 2.58 & 2.31 & 2.56 & 2.47 & 2.31 & 0.040 & 0.060 \\
MAO (U/L) & 25.41 & 24.20 & 28.38 & 25.40 & 26.60 & 0.906 & 0.687 \\
\hline 21 days & & & & & & & \\
CRP(mg/L) & 4.22 & 3.92 & 3.24 & 4.19 & 3.99 & 0.153 & 0.259 \\
LPS(EU/ml) & $0.40^{\mathrm{ab}}$ & $0.44^{\mathrm{a}}$ & $0.41^{\mathrm{ab}}$ & $0.40^{\mathrm{ab}}$ & $0.38^{\mathrm{b}}$ & 0.005 & 0.001 \\
DAO(U/L) & 2.13 & 2.34 & 2.15 & 2.14 & 2.11 & 0.032 & 0.110 \\
MAO (U/L) & $20.81^{\mathrm{ab}}$ & $22.89^{\mathrm{a}}$ & $21.11^{\mathrm{ab}}$ & $19.90^{\mathrm{b}}$ & $19.98^{\mathrm{ab}}$ & 0.353 & 0.039 \\
\hline $\mathbf{4 2}$ days & & & & & & & \\
CRP(mg/L) & 2.99 & 3.73 & 2.33 & 3.05 & 3.40 & 0.193 & 0.187 \\
LPS(EU/ml) & $0.36^{\mathrm{a}}$ & $0.37^{\mathrm{a}}$ & $0.29^{\mathrm{b}}$ & $0.29^{\mathrm{b}}$ & $0.38^{\mathrm{a}}$ & 0.008 & 0.000 \\
DAO(U/L) & $3.20^{\mathrm{a}}$ & $3.15^{\mathrm{a}}$ & $1.84^{\mathrm{b}}$ & $1.65^{\mathrm{b}}$ & $3.87^{\mathrm{a}}$ & 0.171 & 0.000 \\
MAO (U/L) & $1.75^{\mathrm{a}}$ & $1.77^{\mathrm{a}}$ & $1.15^{\mathrm{b}}$ & $1.30^{\mathrm{b}}$ & $1.92^{\mathrm{a}}$ & 0.062 & 0.000
\end{tabular}

${ }^{\mathrm{a}-\mathrm{d}}$ Means with different superscripts within a row were significantly different $(P<0.05)$. DAO $=$ diamine oxidase, $\mathrm{MAO}=$ monoamine oxidase, $\mathrm{LPS}=$ Lipopolysaccharide. $\mathrm{PC}=$ Positive Control, $\mathrm{NC}=$ negative control, $\mathrm{AGP}=10 \mathrm{ppm}$ kitasamycin, $\mathrm{NC} 50=50 \mathrm{ppm} \mathrm{BT}, \mathrm{NC} 100=100 \mathrm{ppm} \mathrm{BT}$.

On the 9 days-old, CRP showed a significant change $(\mathrm{P}<0.05)$. AGP diet contributed to decrease the level of CRP significantly $(\mathrm{P}<0.05)$, and no differences were observedto the other treatments. On 21 days-old and 42 days-old, no treatment effect on CRP was observed. 
However, the dietary treatments influenced the level of LPS inserum on the $9^{\text {th }}$ day significantly $(\mathrm{P}<0.01)$. The chickens from the groups challenged by Salmonella infection demonstrated higher LPS than that in PC, otherwise the BT100 showed differently, and them, the AGP had the highest LPS. On the 21 days-old, similar effects could be witnessed that NC had the highest LPS, and BT100 had the lowest, which imply to no significant differences between them $(p<0.05)$. On the 42 days-old, there was no obvious difference of LPS level among PC, NC and BT100, but the AGP and BT50 had lower LPS level than the former three groups $(\mathrm{P}<0.05)$.

The activity of MAO and DAO serum on 9 days-old of birds were found to have no influence during the treatmens $(\mathrm{P}>0.05)$. However, MAO activity on 21 days-old was affected significantly by Salmonella infection and the dietary treatments $(\mathrm{P}<0.05)$. NC displayed higher MAO activity than that in PC $(\mathrm{P}<0.05)$. Whilst,the addition of AGP and BT decreased the MAO activity tovarying degrees, and among them, BT50 was the lowest $(\mathrm{P}<0.05)$. DAO activity of all groups on days $21^{\text {st }}$ maintained consistently without any effects. Interestingly, like LPS, the activity of MAO and DAO in PC, NC and BT100 groups displayed much higher activities than those from AGP and BT50 $(\mathrm{P}<0.05)$.

\section{Liver Histopathological Analysis}

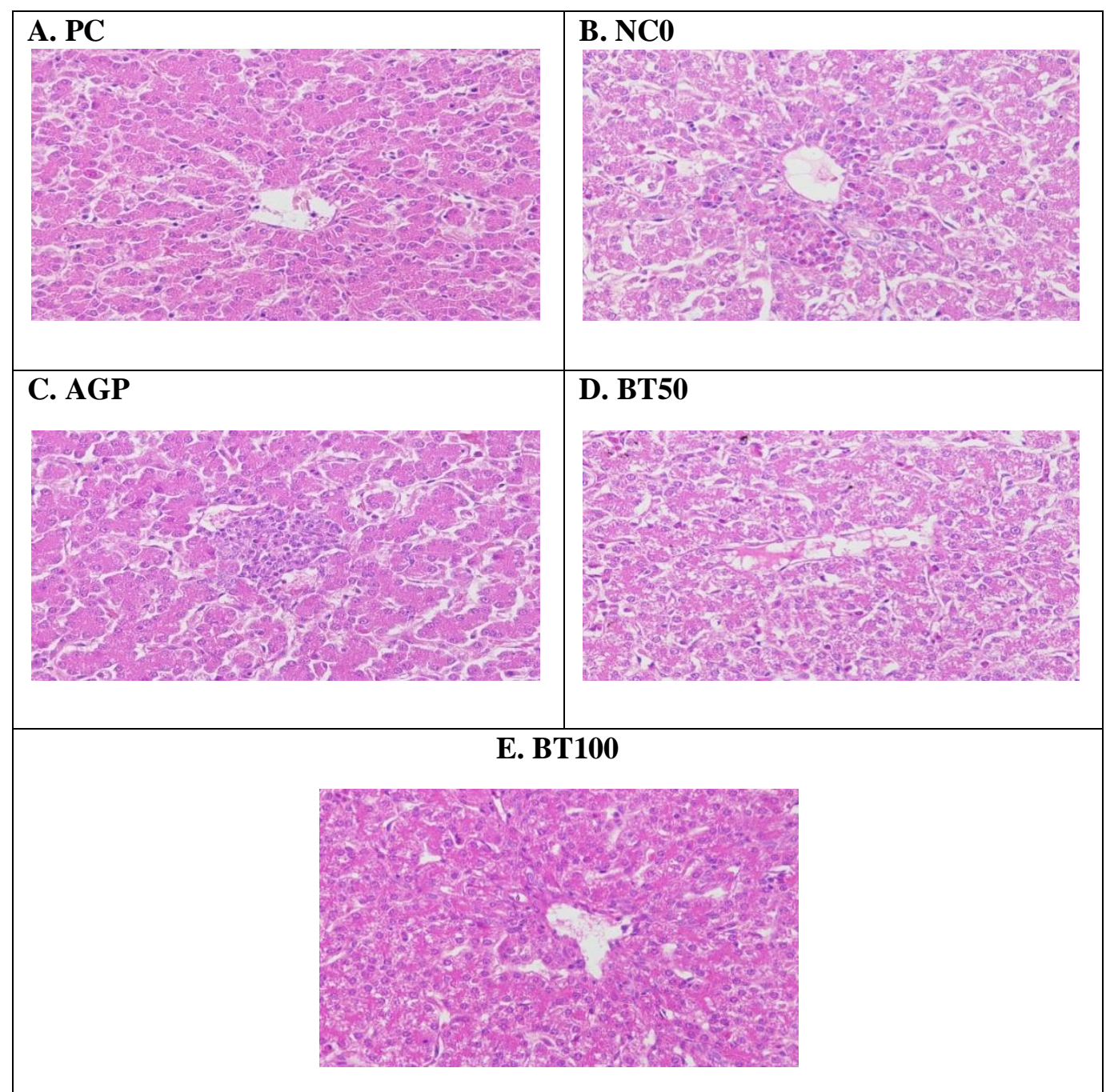

Figure 1.A. Liver from positive control on the day of $21^{\text {st }}$ showed the structure of hepatic plate is welldefined, hepatocytes with evenly painted cytoplasm, normal nuclei and moderately dilated hepaticsinusoid . B. Liver from negative control challenged by salmonella on the day of $21^{\text {st }}$ showed hepatocyte steatosis, allophilic granulocytes infiltrates near pericentral vein.C. Liver from birds dietary administered $10 \mathrm{mg} / \mathrm{kg}$ kitasamycin and challenged by salmonella and on the day of $21^{\text {st }}$ showed the mild hepatocyte steatosis, a few macrophage infiltrates.D. Liver from birds fed 50 ppm BT and chellenged by salmonella on the day $21^{\text {st }}$ showed swelling and steatosis of hepatocytes 
and hepatic congestion. E. Liver from birds chellenged by salmonella and 100 ppm BT administration on the day $21^{\text {st }}$ showed the mild hepatocyte steatosis

Figure 1 shows the change of livers of $21^{\text {st }}$ and $42^{\text {nd }}$ days. Most sections of the liver from PC group on 21 days-old showed normal hepatocytes and tissue structure. Only a few sections showed small or focal infiltration of macrophages, occasional mild steatosis of hepatocytes and mild congestion of liver (Figure 1A). However, a hepatocyte steatosis was more common in the liver of chickens with Salmonella challenge (NC), and there were a few mild or moderate hepatocytes swelling, focal infiltration of inflammatory cell and heterotropic granulocytes and macrophages. Severe heterotropic granulocytes, macrophages infiltration and hepatic congestion could be seen occasionally (Figure 1B).

In the AGP group, most sections showed mild steatosis of hepatocytes, and a few of them showed focal infiltration of macrophages and occasional mild hepatocyte swelling and hepatic congestion (Figure 1C). For BT50 treatment, hepatocyte steatosis was commonly observed. A few of liver congestion, focal necrosis of hepatocytes, mild macrophages infiltrate could be witnessed, and some heterotropic granulocytes infiltrate could be seen occasionally (Figure 1D). In the liver sections from BT100 group, mild and moderate heterotropic steatosis occured commonly, with a few cases of hepatic congestion, focal necrosis of hepatocytegs and a small amount of macrophage infiltration ( Figure 1E). In summary, most of the sections from the samples which were without challenge were observed to be normal, and there were more abnormal hepatocytes from Salmonella infection groups. The NC and BT50 have more serious abnormal phenomena, but AGP and BT100 have less. Seemingly, antibiotics and high doses of BT showed some resistance to salmonella infection. It is suggested that antibiotics and high doses of BT have postive effect against salmonella infection.

\section{Discussion}

Brevibacillusspecies is widely used in agriculture microbiology applications (Seddon et al. 2000; Shindu and Khetarpaul, 2003). However, a little information about their use as probiotic agents is known, and most studies have reported that probiotics from brevibacillus species are commonly Utilized (Shindu and Khetarpaul, 2003). It has been reported that a strain, B. brevis FJAT- 1501-BPA could inhibit the growth of E. Coli K88, Salmonella typhimurium ATCC14028 and Staphylococcus aureus (Ge et al. 2009), which implies to the potential feature as a probiotic in animal feeding. The present study confirmed the speculation above, which displayed the improvement of growth performance of challenged infection by Salmonella pullorumbroiler chickens via the dietary addition of $100 \mathrm{ppm}$ Brevibacillus laterosporus texasporus culture even though it could not overcome the hazards of the pathogen thoroughly. The similar studies also supported our results. It has been reported that the administration of Bacillus brevis FJAT-1501-BPA fermentation to 35 days weaned piglets increased BW by $46.6 \%$ and decreased F/G by $37.1 \%$ (Che et al., 2016). On the other hand, a study has found animal feeds mixed with bacillus can help reducing the feed conversion ratio in pigs(Guo, Li, Lu, Piao, \& Chen, 2006). The supplementation of broiler feed with Bacillus subtilis and B. licheniformis improved the feed conversion efficiency(Shim et al., 2012). Similarly, significant results have been reported via feed conversion efficiency in White Leghorn Breeders stock during (25- 40 weeks of age of birds) with dietary inclusion of Bacillus subtilis and B. licheniformis (at the rate of $6 \times 10^{8}$ spores per kg of diet) (Panda, Rao, Raju, \& Sharma, 2006).

In order to discover the benificial mechanism of Bacillus for development and growth of animals, researchers have proposed some hypotheses. Most of them suggested that the beneficial effects of Bacillus could root in the function of probiotics as antioxidants, antibacterial, anti-fungi, antiprotozoa, and immunopotentiator (Leung and Foster, 1996); (Bandaiphet \& Kennedy, 2004). Plentiful evidences supported these hypotheses directly or indirectly. However, the beneficial effects of Bacillus brevis texasporus for animals have not been revealed well. Only few reports indicated that the immunoenhancement activity of BT peptide, and a postively charged lipopeptide produced by Bacillus brevis texasporus, could account to the advantage of this strain. Kogut et al $(2007,2009)$ has reported that BT peptide accelerated the innate immune function of chicken, and it up-regulated the heterophils function by the increasing phagocytosis, oxidative burst, degranulation, and enhancing the function actvity of peripheral boold monocytes by increasing NO synthesis and oxidative burst. Immounoglobulins are important immune substance, which are produced by B-cell stimulated by pathogen. To further confirm the immunoenhencement activity of Bacillus brevis texasporus, the level changes of Immounoglobulins (IgA, IgG, IgM) in serum were determine.It was found that 100 
$\mathrm{mg} / \mathrm{kg}$ BT overcame the suppression effect of Salmonella on IgG and IgM partly on 9 days of age. On the day of 21, Salmonella increased the IgM level in serum, and $100 \mathrm{mg} / \mathrm{kg}$ BT reversed the change to some extent. Previously, Salmonella infectioninhibited the immune system of chickens aged 9 days. The suppression effect of Salmonella for immune system was reported by Rheinallt (2008). However, the suppression seems to fade away as time goes by, and immunoglobulins themselves werestimulated by theSalmonella infection. A study in 2006 has also demonstrated that infection by Salmonella Typhimurium induces a high level of specific antibodies, but the B-cells have no an essential role in clearance of primary infection or in the enhanced clearance after secondary challenge(Beal, Wigley, Powers, Barrow, \& Smith, 2006). At all events, BT showed its positive effects on resisting the influence of Salmonella infection on humoral immunity.

Verterinary studies have found that Salmonella pullorum infection per os could produce virulence factors, including endotoxin and VP (Virulent plasmid), and in the animal intestine, the endotoxin could induce immunocompetent cell to release cytokine and further to cause local or systemic inflammatoryreaction. Some enzymes and molecular effects are used as inflammatory markers, which include the C-reactive protein, endotoxins and some iso-enzymes.

C-reactive protein (CRP) in serum level is a molecular systemic effect. Its level has been known to increase dramatically in response to injury, infection, and inflammation. CRP is mainly classed as an acute marker of inflammation, but a research starts to indicate important roles that CRP plays in inflammation. Our study has found no obvious increasing of CRP level in challenged birds at any days-age. However, the level of CRP in birds aged 42-days tend to increase and decrease by the BT and antibiotics. The CRP is the principal downstream mediator of the acute-phase response following an inflammatory event, and it is primarily synthesized by IL-6-dependent hepatic biosynthesis (Pradhan, Manson, Rifai, Buring, \& Ridker, 2001). The main role of CRP in inflammation tends to focus around the activation of the $\mathrm{Clq}$ molecule in the complement pathway leading to the opsonization of pathogens. Although the CRP can initiate the fluid phase pathways of the host defense by activating the complement pathway, it can also initiate cell-mediated pathways by activating complement as well as to binding to Fc receptors of IgG (Baumeister, Freeman, Dranoff, \& Sharpe, 2016) . CRP binds to Fc receptors with the resulting interaction leading to the release of proinflammatory cytokines.

The endotoxin released by Salmonella pullorum is mainly lipopolysaccharide (LPS), which is a glycolipid presented in the outer membrane of Gram-negative bacterial cell wall. LPS consists of a hydrophobic domain, lipid A, through which it is inserted into the bacterial cell wall a core oligosaccharide, and a distal oligosaccharide (RAETZ \& WHITFIELD, 2008). Our results indicated that the chickens challenged infection by Salmonella displayed a higher level of LPS, and birds fed anibiotics expressed the highest LPS. On the 21 days-old, similar effects could be witnessed that Salmonella infection increased the LPS level and $100 \mathrm{mg} / \mathrm{kg}$ BT decreased the level. LPS derived from the debris of Salmonella are destroyed by chemicals or immune system. The strong bacteriostaticactivity of antibiotics could destroy LPS quickly and increased LPS rapidly at 9 daysold (only two days after challenging). Compared with antibiotics, BT seems to develope effect slowly and display its postive effect at 21 days-age.

The intestinal mucosa has an important barrier function in health and disease (Turner, 2009). Salmonella can attach to and invade the intestinal mucosa and multiply in the hosts cells, and they can produce toxins and affect gut microflora, causing direct injury to the intestine (Stravic \& D'aoust, 1993). DAO is an enzyme synthesized primarily in the gastrointestinal mucosal cells. The activity of DAO in serum increases when the mucosa is damaged due to itspenetration to the bloodstream (Yang et al., 2012). Serum DAO activity is a useful biomarker for evaluating the integrity of the gastrointestinal tract (Wu et al., 2014). The present results showed that serum DAO of broilers remains unchanged even though they were challenged with Salmonella. However, antibiotics and 50 $\mathrm{mg} / \mathrm{kg}$ BT decreasedthe DAO activity significantly.

Liver is another important organ attacked by Salmonella. Monoamine oxidase (MAO) is mainly distributed in liver, kidney and brain. The increase of MAO activity in serum often means hepatic injury. In the present study, we found Salmonellapullorum infection increased the MAO activity in serum significantly, and antibiotics or Bacillus lateropus texasporus culture can reduce the MAO level on 21 days of age. In the day of 42 , antibiotics and $50 \mathrm{mg} / \mathrm{kg}$ BT decreased the MAO activity as well. The results were consistent with the histopathological observation. Liver 
histopathological analysis implied that Salmonellapullorum infection resulted in apparent hepatocyte steatosis, hepatocytes swelling, focal infiltration of inflammatory cell and heterotropic granulocytes and macrophages, which should destroy liver tissue and released MAO into blood, and antibiotics and BT could eliminate the adverse changes of liver tissue partly.

Although the limited evidences in this study could be enough to illustrate the mechanism of BT, we still confirmed that BT is capable to protect the chicken from Salmonellapullorum infection to some extent. Even more remarkable, BT has shown a similar effect to antibiotics for growth which implies its potential to be used as an alternative of antibiotics in poultry feed.

\section{CONCLUSION}

In conclusion, the results presented in this study indicate that Brevibacillus laterosporus texasporus culture with $100 \mathrm{mg} / \mathrm{kg}$ in feed could improve the growth performance of broiler chickens which have been challenged by Salmonella infection. Brevibacillus laterosporus texasporus culture also inhibited the inflammation response of chickens induced by Salmonella, and reverse the intestine and liver injury caused by Salmonella. This suggests Brevibacillus laterosporus texasporus culture can be used as a feed additive to promote health, growth, and increasing performance of broilers chickens.

\section{ACKNOWLEDGEMENT}

We are thankful to Beijing Innovation Consortium Of The Poultry Industry Research System Of China (BAIC04-2019) for funding this study, we are also grateful to the staff of Laboratory Of Feed Biotechnology Of Agricultural Ministry, Feed Research Institute, GSCAAS, Beijing, for the technical assistance.

\section{REFERENCES}

[1] Afsharmanesh, M., Sadaghi, B., \& Silversides, F. G. (2013). Influence of supplementation of prebiotic , probiotic, and antibiotic to wet-fed wheat-based diets on growth, ileal nutrient digestibility, blood parameters , and gastrointestinal characteristics of broiler chickens. 245-251. https://doi.org/10.1007/s00580-011-1393-2

[2] Bandaiphet, C., \& Kennedy, J. F. (2004). Encyclopedia of Common Natural Ingredients used in Food, Drugs and Cosmetics (2nd Edition). In Carbohydrate Polymers (Vol. 58). https://doi.org/10.1016/j.carbpol.2004.05.002

[3] Bapat, S., \& Shah, A. K. (2000). Biological control of fusarial wilt of pigeon pea by Bacillus brevis. Canadian Journal of Microbiology, 46(2), 125-132. https://doi.org/10.1139/w99-109

[4] Baumeister, S. H., Freeman, G. J., Dranoff, G., \& Sharpe, A. H. (2016). Coinhibitory Pathways in Immunotherapy for Cancer. Annual Review of Immunology, 34(1), 539-573. https://doi.org/10.1146/annurev-immunol-032414-112049

[5] Beal, R. K., Wigley, P., Powers, C., Barrow, P. A., \& Smith, A. L. (2006). Cross-reactive cellular and humoral immune responses to Salmonella enterica serovars Typhimurium and Enteritidis are associated with protection to heterologous re-challenge. Veterinary Immunology and Immunopathology, 114(1-2), 84-93. https://doi.org/10.1016/j.vetimm.2006.07.011

[6] Che, J., Liu, B., Ruan, C., Tang, J., \& Huang, D. (2015). Biocontrol of Lasiodiplodia theobromae, which causes black spot disease of harvested wax apple fruit, using a strain of Brevibacillus brevis FJAT-0809GLX. Crop Protection, 67, 178-183. https://doi.org/10.1016/j.cropro.2014.10.012

[7] Che, J., Ye, S., Liu, B., Deng, Y., Chen, Q., Ge, C., ... Wang, J. (2016). Effects of Brevibacillus brevis FJAT-1501-BPA on growth performance, faecal microflora, faecal enzyme activities and blood parameters of weaned piglets. Antonie van Leeuwenhoek, International Journal of General and Molecular Microbiology, 109(12), 1545-1553. https://doi.org/10.1007/s10482-016-0756-8

[8] Ge CB, Liu B, Lan JL, Huang SF, Zhu YJ. The anti-bacterial activity research of biocontrol bacteria JK-2 on Fusarium oxysporum. Fujian J Agric Sci 2009;24:29-34.

[9] Guo, X., Li, D., Lu, W., Piao, X., \& Chen, X. (2006). Screening of Bacillus strains as potential probiotics and subsequent confirmation of the in vivo effectiveness of Bacillus subtilis MA139 in pigs. Antonie van Leeuwenhoek, International Journal of General and Molecular Microbiology, 90(2), 139-146. https://doi.org/10.1007/s10482-006-9067-9

[10] Karimi-Kivi, R., Dadashbeiki, M., \& Seidavi, A. (2015). Growth, body characteristics and blood parameters of ostrich chickens receiving commercial probiotics. Spanish Journal of Agricultural Research, 13(1). https://doi.org/10.5424/sjar/2015131-6146

[11] Leung, A.Y. and Foster, S. (1996) Encyclopedia of Common Natural Ingredients Used in Food, Drugs and Cosmetics. 2nd Edition, John Wiley and Sons, Inc., New York. 
[12] Page, S. W., \& Gautier, P. (2012). Use of antimicrobial agents in livestock. OIE Revue Scientifique et Technique, 31(1), 145-188. https://doi.org/10.20506/rst.31.1.2106

[13] Panda, A. K., Rao, S. V. R., Raju, M. V. L. N., \& Sharma, S. R. (2006). Dietary supplementation of lactobacillus sprogenes on performance and serum biochemico lipid profile of broiler chickens. The Journal of Poultry Science, 43:, 235-240.

[14] Pradhan, A. D., Manson, J. E., Rifai, N., Buring, J. E., \& Ridker, P. M. (2001). C-reactive protein, interleukin 6, and risk of developing type 2 diabetes mellitus. Journal of the American Medical Association, 286(3), 327-334. https://doi.org/10.1001/jama.286.3.327

[15] Raetz, C. R. H., \& Whitfield, C. (2008). Lipopolysaccharide Endotoxins Endotoxins as Activators of Innate Immunity. Annual Review of Biochemistry, 71, 635-700. https://doi.org/10.1146/annurev.biochem.71.110601.135414

[16] Seddon B, McHugh RC, Schmitt A. Brevibacillus brevis - a novel candidate biocontrol agent with broadspectrum antifungal activity. In: The BCPC conference: pests and diseases, 2. Proceedings of an international conference held at the Brighton Hilton Metropole Hotel; 2000. p. 563-70.

[17] Shim, Y. H., Ingale, S. L., Kim, J. S., Kim, K. H., Seo, D. K., Lee, S. C., ... Kwon, I. K. (2012). A multimicrobe probiotic formulation processed at low and high drying temperatures: effects on growth performance, nutrient retention and caecal microbiology of broilers. British Poultry Science, 53(4), 482490. https://doi.org/10.1080/00071668.2012.690508

[18] Sindhu, S. C. and N. Khetarpaul. 2003. Effect of feeding probiotic fermented indigenous food mixture on serum cholesterol levels in mice. Nutr. Res. 23:1071-1080.

[19] Stravic, S., \& D'aoust, J.-Y. (1993). Undefined and Defined Bacterial Preparations for the Competitive Exclusion of Salmonella in Poultry - A Review. Journal of Food Protection, 56(2), 173-180. https://doi.org/10.4315/0362-028x-56.2.173

[20] Suo, C., Yin, Y., Wang, X., Lou, X., Song, D., Wang, X., \& Gu, Q. (2012). Effects of lactobacillus plantarum ZJ316 on pig growth and pork quality. BMC Veterinary Research, 8(198). https://doi.org/10.1186/1746-6148-8-89

[21] Turner, J. R. (2009). Intestinal mucosal barrier function in health and disease. Nature Reviews Immunology, 9(11), 799-809. https://doi.org/10.1038/nri2653

[22] Wu, M., Xiao, H., Ren, W., Yin, J., Tan, B., Liu, G., ... Wu, G. (2014). Therapeutic effects of glutamic acid in piglets challenged with deoxynivalenol. PLoS ONE, 9(7), 1-12. https://doi.org/10.1371/journal.pone.0100591

[23] Wu, X., Ballard, J., \& Jiang, Y. W. (2005). Structure and biosynthesis of the BT peptide antibiotic from Brevibacillus texasporus. Applied and Environmental Microbiology, 71(12), 8519-8530. https://doi.org/10.1128/AEM.71.12.8519-8530.2005

[24] Yang, C. M., Ferket, P. R., Hong, Q. H., Zhou, J., Cao, G. T., Zhou, L., \& Chen, A. G. (2012). Effect of chito-oligosaccharide on growth performance, intestinal barrier function, intestinal morphology and cecal microflora in weaned pigs. Journal of Animal Science, 90(8), 2671-2676. https://doi.org/10.2527/jas.2011-4699 